\title{
A study of epidemiological and clinical profile of ovarian neoplasms at a tertiary care hospital
}

\section{Priyadarshika M.*}

Department of Obstetrics and Gynecology, Malla Reddy Medical College for Women, Suraram, Hyderabad, Telangana, India

Received: 22 February 2018

Accepted: 28 March 2018

\section{*Correspondence:}

Dr. Priyadarshika M,

E-mail: dr_priyadarshika@yahoo.com

Copyright: (c) the author(s), publisher and licensee Medip Academy. This is an open-access article distributed under the terms of the Creative Commons Attribution Non-Commercial License, which permits unrestricted non-commercial use, distribution, and reproduction in any medium, provided the original work is properly cited.

\begin{abstract}
Background: The cancer of the ovaries tends to remain asymptomatic. Hence better understanding of the natural history of disease is essential for prevention. The objective of the present study was to observe the epidemiological and clinical profile of women with ovarian neoplasms at a tertiary care hospital.

Methods: A hospital based cross sectional study was carried out among women of age up to 35 years presenting to the Obstetrics and Gynecology Department of our hospital during the study period of two years. It was possible to study a total of 56 women in the present study as per the inclusion and exclusion criteria laid down for the present study.

Results: T It was found that maximum cases were in the age group of 26-30 years (42.9\%). Majority of the women were nulliparous $(46.5 \%)$. The most commonly reported symptom of ovarian tumor was abdominal pain in $62.5 \%$ of the cases. $50 \%$ of women having menstrual symptoms complained of amenorrhea. There were 11 cases associated with pregnancy. Among them, four (36.4\%) were of dermoid cyst. There were 9 cases of torsion. Among them maximum (55.6\%) were of dermoid cyst. Maximum tumors $(92.9 \%)$ were unilateral. Maximum tumors $(73.2 \%)$ were of size less than $10 \mathrm{~cm}$. maximum tumors (53.6\%) were cystic with solid component. Ascites was seen in $14.2 \%$ of the cases.

Conclusions: As the age increased the incidence of the ovarian neoplasms also increased. Bilaterality, small size and cystic nature were the most common features of the ovarian neoplasms. Though majority was simple, complications like torsion, association with pregnancy can be seen and hence thorough investigations are needed.
\end{abstract}

Keywords: Infertility ovarian neoplasm, Pregnancy, Torsion

\section{INTRODUCTION}

Globally it has been estimated that the incidence of cancer of ovaries is 239 thousand yearly. Every year 152 thousand die due to cancer of ovary all over the world. ${ }^{1}$

Cancer of ovary is more prevalent in European countries. The estimates say that the incidence rates are 11.4 per one lakh population in this region. China reports the lowest incidence in the world. It is 4.1 per one lakh population over there. But considering the huge population of China, as many as more than 50,000 cases occur there and more than 20,000 die every year in China. ${ }^{2}$ Comparatively the incidence and mortality from cancer of the ovaries is less in USA. ${ }^{3}$

As per the statistics available, 1 in every 75 women can develop cancer of the ovary and 1 in every 100 women can die due to cancer of the ovary. ${ }^{4}$ As a rule given for neoplasms, the cancer of the ovary also remains asymptomatic in the initial stages and by the time it is noticed, it has already entered into the late stages where 
the survival rates go down drastically. Only about $15 \%$ of the cases of the cancer of the ovary can be diagnosed when there is a localized tumor and in such fortunate cases the survival rate is more than $90 \% .{ }^{4}$ Overall, average five-year survival rate for patients of the cancer of the ovaries ranges between $30-40 \% .^{5}$

In European countries, cancer of the ovaries stands at fifth place in the list of most common cancers among European women. Poor survival is due to lack of knowledge of natural history of the disease and delayed diagnosis of the cancer of ovary.

Research has been done to study the role of hormones in the pathogenesis of the cancer of the ovaries. Having more children, use of oral pills of contraception and the hysterectomy were shown as protective factors for the cancer of the ovaries.

But when the pill use should be started is not clear and also what should be the age at which first birth should occur is also not clear. The role of other factors in the pathogenesis of the cancer of the ovary is also not clear. ${ }^{6}$

Reduced fertility has been shown to be associated with the more risk of developing the cancer of the ovaries. But the strong association has not been still found. But maximum studies show some kind of association. ${ }^{7}$

A pooled analysis was carried out taking ten case control studies. It was found that parity and oral pill use were associated inversely with the cancer of the ovaries. In USA cancer of the ovaries stand at fourth place in the list of most common cancer among US women. The cancer of the ovaries tends to remain asymptomatic. Hence better understanding of the natural history of disease is essential for prevention. ${ }^{8}$

Regular physical activity may act as a protective factor in the occurrence of the cancer of the ovaries. Regular physical activity leads to decrease in the fat of the body. These low levels among women affect the estrogen levels and the estrogen goes down. Because of this, frequency of the ovulation gets lowered. This leads to reduced inflammation in the ovaries thereby reducing the risk of the cancer of the ovaries. ${ }^{9}$

\section{METHODS}

A hospital based cross sectional study was carried out among women of age up to 35 years presenting to the Obstetrics and Gynecology Department of our hospital during the study period of two years. It was possible to study a total of 56 women in the present study as per the inclusion and exclusion criteria laid down for the present study.

\section{Inclusion criteria}

- All women aged 35 years or less
- Women willing to participate in the present study

- Women having confirmed diagnosis of tumor of the ovary

\section{Exclusion criteria}

- Women more than 35 years of age

- Women not willing to participate in the present study

- Seriously ill women who were unable to participate in the present study

Thus, a total of 56 women could be studied as the abovementioned inclusion and exclusion criteria during the study period of two years in the present study.

Before the start of the study, the study protocol was submitted to the Institutional Ethics Committee and after we got the approval from the committee we started the actual data collection.

Any woman as per inclusion and exclusion criteria presenting to the department of Obstetrics and Gynecology with tumor of the ovary was asked her willingness to participate in the present study.

The data was recorded in the study proforma. Detailed history like age, parity was recorded. Symptoms like abdominal pain, distension of the abdomen, feeling of mass in the abdomen, symptoms related to irregularities of the menstruation, gastrointestinal symptoms, urinary symptoms, any history of prolapse per vaginum, and history of infertility was enquired into.

Menstrual irregularities like amenorrhea, menorrhagia, and polymenorrhea were recorded. In 11 cases we found that the ovarian tumor was associated with pregnancy. In nine cases we found that there was torsion.

For all women ultra-sonography of abdomen and pelvis was carried out after ensuring the full bladder. The ultrasonography was done specifically with respect to the site of the tumor of the ovary, size of the tumor of the ovary, echogenecity of the tumor of the ovary and presence or absence of ascites.

The data was carefully recorded, entered and analyzed using proportions.

\section{RESULTS}

Table 1 shows distribution of study subjects as per age. It was found that maximum cases were in the age group of 26-30 years (42.9\%) followed by $31-35$ years i.e. $28.6 \%$. It has been observed that as the age increased, the incidence of tumor of the ovary increased.

Table 2 shows distribution of study subjects as per their parity. Majority of the women were nulliparous (46.5\%). There was only one woman with parity of four. Parity 
two was seen in $21.4 \%$ of the women and parity one was seen in $19.6 \%$ of the women.

Table 1: Distribution of study subjects as per age.

\begin{tabular}{|lll|}
\hline Age (years) & Number & $\%$ \\
\hline$<10$ & 0 & 0 \\
\hline $11-15$ & 2 & 3.5 \\
\hline $16-20$ & 5 & 8.9 \\
\hline $21-25$ & 9 & 16.1 \\
\hline $26-30$ & 24 & 42.9 \\
\hline $31-35$ & 16 & 28.6 \\
\hline Total & 56 & 100 \\
\hline
\end{tabular}

Table 2: Distribution of study subjects as per their parity.

\begin{tabular}{|lll|}
\hline Parity & Number & $\%$ \\
\hline 0 & 26 & 46.5 \\
\hline 1 & 11 & 19.6 \\
\hline 2 & 12 & 21.4 \\
\hline 3 & 6 & 10.7 \\
\hline 4 & 1 & 1.8 \\
\hline Total & 56 & 100 \\
\hline
\end{tabular}

Table 3 shows distribution of study subjects as per their symptoms. The most commonly reported symptom of ovarian tumor was abdominal pain in $62.5 \%$ of the cases followed by mass in the abdomen in $32.1 \%$ of the cases. There were only two cases of infertility and only one case of prolapse of mass per vaginum. Menstrual symptoms were reported in eight cases.

Table 3: Distribution of study subjects as per their symptoms.

\begin{tabular}{|lll|}
\hline Symptoms & Number & $\%$ \\
\hline Abdominal pain & 35 & 62.5 \\
\hline Abdominal mass & 18 & 32.1 \\
\hline Distension & 5 & 8.9 \\
\hline Menstrual symptoms & 8 & 14.1 \\
\hline Gastrointestinal symptoms & 5 & 8.9 \\
\hline Urinary symptoms & 3 & 5.3 \\
\hline Prolapse (mass per vaginum) & 1 & 1.8 \\
\hline Infertility & 2 & 3.6 \\
\hline
\end{tabular}

Table 4 shows incidence of menstrual symptoms. Out of 56 cases studied in the present study, only 8 cases reported menstrual symptoms.

Table 4: Incidence of menstrual symptoms $(\mathbf{N}=8)$.

\begin{tabular}{|lll|}
\hline Type of menstrual disturbance & Number & $\%$ \\
\hline Amenorrhea & 4 & 50 \\
\hline Menorrhagia & 3 & 37.5 \\
\hline Polymenorrhoea & 1 & 12.5 \\
\hline Total & 8 & 100 \\
\hline
\end{tabular}

$50 \%$ of women having menstrual symptoms complained of amenorrhea and $37.5 \%$ of them complained of menorrhagia. Table 5 shows ovarian tumors associated with pregnancy. There were 11 cases which were found to be associated with pregnancy. Among them, four (36.4\%) were of dermoid cyst and four $(36.4 \%)$ were of serous cystadenoma. Two were of mucinous cystadenoma and one case was of Low malignant potential mucinous tumor.

Table 5: Ovarian tumors associated with pregnancy ( $\mathbf{N}=11)$.

\begin{tabular}{|lll|}
\hline Type of tumor & Number & $\%$ \\
\hline Dermoid cyst & 4 & 36.4 \\
\hline Serous cystadenoma & 4 & 36.4 \\
\hline Mucinous cystadenoma & 2 & 18.2 \\
\hline Low MPMT & 1 & 9 \\
\hline Total & 11 & 100 \\
\hline
\end{tabular}

Table 6 shows incidence of torsion. There were 9 cases of torsion. Among them maximum $(55.6 \%)$ were of dermoid cyst followed by $33.3 \%$ of the serous cystadenoma. Only one case was of mucinous cystadenoma.

Table 6: Incidence of torsion $(\mathbf{N}=9)$.

\begin{tabular}{|lll|}
\hline Type of tumor & Number & $\%$ \\
\hline Dermoid cyst & 5 & 55.6 \\
\hline Serous cystadenoma & 3 & 33.3 \\
\hline Mucinous cystadenoma & 1 & 11.1 \\
\hline Total & 9 & 100 \\
\hline
\end{tabular}

Table 7 shows distribution as per the Ultrasonographic findings. Maximum tumors $(92.9 \%)$ were unilateral. Maximum tumors (73.2\%) were of size less than $10 \mathrm{~cm}$. maximum tumors $(53.6 \%)$ were cystic with solid component. Ascites was seen in $14.2 \%$ of the cases.

Table 7: Distribution as per the Ultrasonographic findings.

\begin{tabular}{|llll|}
\hline USG feature & & Number & $\%$ \\
\hline $\begin{array}{l}\text { Site of } \\
\text { involvement }\end{array}$ & Unilateral & 52 & 92.9 \\
\cline { 2 - 4 } & Bilateral & 4 & 7.1 \\
\hline \multirow{3}{*}{ Size } & $<10 \mathrm{~cm}$ & 41 & 73.2 \\
\cline { 2 - 4 } & $11-20 \mathrm{~cm}$ & 11 & 19.6 \\
\cline { 2 - 4 } & $>20 \mathrm{~cm}$ & 4 & 7.2 \\
\hline \multirow{3}{*}{ Echogenecity } & Cystic & 21 & 37.5 \\
\cline { 2 - 4 } & $\begin{array}{l}\text { Cystic with solid } \\
\text { component }\end{array}$ & 30 & 53.6 \\
\cline { 2 - 4 } & Solid & 5 & 8.9 \\
\hline Ascites & & 8 & 14.2 \\
\hline
\end{tabular}

\section{DISCUSSION}

It was found that maximum cases were in the age group of 26-30 years (42.9\%) followed by 31-35 years i.e. 
$28.6 \%$. It has been observed that as the age increased, the incidence of tumor of the ovary increased. Majority of the women were nulliparous $(46.5 \%)$. There was only one woman with parity of four. Parity two was seen in $21.4 \%$ of the women and parity one was seen in $19.6 \%$ of the women. The most commonly reported symptom of ovarian tumor was abdominal pain in $62.5 \%$ of the cases followed by mass in the abdomen in $32.1 \%$ of the cases. There were only two cases of infertility and only one case of prolapse of mass per vaginum. Menstrual symptoms were reported in eight cases. Out of 56 cases studied in the present study, only 8 cases reported menstrual symptoms. $50 \%$ of women having menstrual symptoms complained of amenorrhea and $37.5 \%$ of them complained of menorrhagia.

There were 11 cases which were found to be associated with pregnancy. Among them, four (36.4\%) were of dermoid cyst and four (36.4\%) were of serous cystadenoma. Two were of mucinous cystadenoma and one case was of Low malignant potential mucinous tumor. There were 9 cases of torsion. Among them maximum $(55.6 \%)$ were of dermoid cyst followed by $33.3 \%$ of the serous cystadenoma. Only one case was of mucinous cystadenoma. Maximum tumors $(92.9 \%)$ were unilateral. Maximum tumors $(73.2 \%)$ were of size less than $10 \mathrm{~cm}$. maximum tumors $(53.6 \%)$ were cystic with solid component. Ascites was seen in $14.2 \%$ of the cases.

Risch HA et al., observed in their case control study that more number of children as well as oral pill use were the protective factors against the cancer of the ovaries. ${ }^{10}$ Hysterectomy was also found to be associated with minimum risk of the cancer of the ovaries.

Goff BA et al., found that abdominal pain was present in $22 \%$ of the cases. This observation was very low compared to the finding of the present study where we found that $62 \%$ of the cases had abdominal pain. The author reported presence of urinary symptoms in $16 \%$ of the cases which is three times more than the finding of the present study. The author found that women with malignant tumors suffered many times more than women with benign tumors. The author stressed the importance of thorough investigations among symptomatic women. ${ }^{11}$

Hamilton W et al., studied the symptoms associated with the cancer of the ovaries. They found that abdominal distension; postmenopausal bleeding; loss of appetite; increased urinary frequency; abdominal pain; rectal bleeding; and abdominal bloating were the most commonly associated symptoms with the cancer of the ovaries. We also found that abdominal distension; increased urinary frequency and abdominal pain were the common symptoms associated with the cancer of the ovaries.

The author concluded that these symptomatic women must be investigated properly to diagnose the cancer of the ovaries in early stages. ${ }^{12}$ Hippisley-Cox $\mathrm{J}$ et al., found that women with family history of the cancer of the ovaries were at 9.8 times more risk of developing the cancer of the ovaries than women without the history of the cancer of the ovaries. Abdominal pain was 7 times more among the women with cancer of the ovaries than women without cancer of the ovaries. Abdominal distension was 23 times more among the women with cancer of the ovaries than women without cancer of the ovaries. Rectal bleeding was 2 times more among the women with cancer of the ovaries than women without cancer of the ovaries. Post-menopausal bleeding was 6.6 times more among the women with cancer of the ovaries than women without cancer of the ovaries. Loss of appetite was 5.2 times more among the women with cancer of the ovaries than women without cancer of the ovaries. Weight loss was 2 times more among the women with cancer of the ovaries than women without cancer of the ovaries. ${ }^{13}$

Permuth-Wey $\mathbf{J}$ et al., stated that age and family history of the cancer of the ovaries were the well known risk factors of the cancer of the ovaries. The author also said that the factors like more parity, use of oral pills, are the protective factors of cancer of the ovaries. ${ }^{14}$

La Vecchia $\mathrm{C}$ et al., presented the overview of the epidemiology of the cancer of the ovaries from the results of a study. They also found that more parity, use of oral pills, is the protective factors of cancer of the ovaries. They noted that there was a limited role of the hormonal and menstrual factors. Mucinous type of cancer was associated with tobacco use. ${ }^{15}$

Riman $\mathrm{T}$ et al., noted that risk of ovarian tumor was less among women who were breast feeding in their life time. Women with live births carried a decreased risk of serous tumor and tumor of mucinous nature. In their study they found that use of oral pills was not a protective factor for serous tumor and tumor of mucinous nature. ${ }^{16}$

Huusom LD et al., also reported similar findings in their study. Increasing parity was associated with reduced risk of the cancer of the ovaries. Increasing age at first birth was also associated with reduced risk of the cancer of the ovaries.

Breasting was also associated with reduced risk of the cancer of the ovaries. Use of oral pills was also associated with reduced risk of the cancer of the ovaries. Higher body mass index was associated with increased risk of the cancer of the ovaries. The strongest risk factor was current smoking. ${ }^{17}$

Soeggard $\mathrm{M}$ et al., noted that being pregnant associated with reduced risk of the cancer of the ovaries. Increasing age at first birth was also associated with reduced risk of the cancer of the ovaries. Use of oral pills was also associated with reduced risk of the cancer of the ovaries. More years of ovulation was associated with increased risk of the cancer of the ovaries. ${ }^{18}$ 


\section{CONCLUSION}

As the age increased the incidence of the ovarian neoplasms also increased. Bilaterality, small size and cystic nature were the most common features of the ovarian neoplasms. Though majority was simple, complications like torsion, association with pregnancy can be seen and hence thorough investigations are needed.

Funding: No funding sources

Conflict of interest: None declared

Ethical approval: The study was approved by the Institutional Ethics Committee

\section{REFERENCES}

1. Ferlay J, Soerjomataram I, Ervik M, Dikshit R, Eser S, Mathers C, et al. GLOBOCAN 2012 v1.0, Cancer Incidence and Mortality Worldwide: IARC CancerBase No. 11. Lyon, France: International Agency for Research on Cancer, 2013[2016-09-09].

2. Chen WQ, Zheng RS, Baade PD, Zhang SW, Zeng HM, Bray F, et al. Cancer statistics in China, 2015. CA Cancer J Clin. 2016;66:115-32.

3. American Cancer Society. Cancer Facts \&amp; Figures 2015. Atlanta: American Cancer Society, 2015.

4. Howlader N, Noone AM, Krapcho M, Neyman N, Aminou R, Waldron W, et al. SEER Cancer Statistics Review, 1975-2008, National Cancer Institute. Bethesa, http://seer.cancer.gov/csr/1975_2008/,

5. Allemani C, Weir HK, Carreira H, Harewood R, Spika D, Wang XS, et al. Global surveillance of cancer survival 1995-2009: analysis of individual data for 25676887 patients from 279 populationbased registries in 67 countries (CONCORD-2) Lancet. 2015;385:977-1010.

6. Ferlay J, Autier P, Boniol M, et al. Estimates of the cancer incidence and mortality in Europe in 2006. Ann Oncol. 2007;18:581-92.

7. Adami HO, Hsieh CC, Lambe M, et al. Parity, age at first childbirth, and risk of ovarian cancer. Lancet. 1994;344:1250-4.

8. Purdie DM, Webb PM, Siskind V, Bain CJ, Green AC. The different etiologies of mucinous and nonmucinous epithelial ovarian cancers. Gynecol Oncol. 2003;88:S145-8.

9. Jordan SJ, Whiteman DC, Purdie DM, Green AC, Webb PM. Does smoking increase risk of ovarian cancer? A systematic review. Gynecol Oncol. 2006;103:1122-9.

10. Risch HA, Marrett LD, Howe GR. Parity, contraception, infertility, and the risk of epithelial ovarian cancer. Am J Epidemiol. 1994;140:585-97.

11. Goff BA, Mandel LS, Melancon CH, Muntz HG. Frequency of symptoms of ovarian cancer in women presenting to primary care clinics. J Am Med Assoc. 2004;291:2705-12.

12. Hamilton W, Peters TJ, Bankhead C, Sharp D. Risk of ovarian cancer in women with symptoms in primary care: population based case-control study. Br Med J. 2009;339:b2998.

13. Hippisley-Cox J, Coupland C. Identifying women with suspected ovarian cancer in primary care: derivation and validation of algorithm. BMJ 2011 ;344:d8009.

14. Permuth-Wey J, Sellers TA. Epidemiology of ovarian cancer. Methods Mol Biol. 2009;472:413-37.

15. La Vecchia C. Ovarian cancer: epidemiology and risk factors. Eur J Cancer Prev. 2017;26:55-62.

16. Riman T, Dickman PW, Nilsson S, Correia N, Nordlinder H, Magnusson CM et al. Risk factors for epithelial borderline ovarian tumors: results of a Swedish case-control study. Gynecol Oncol 2001;83:575-85.

17. Huusom LD, Frederiksen K, Hogdall EV, Glud E, Christensen L, Hogdall CK et al. Association of reproductive factors, oral contraceptive use and selected lifestyle factors with the risk of ovarian borderline tumors: a Danish case-control study. Cancer Caus Cont. 2006;17:821-9.

18. Soeggard M, Jensen A, Hogdall E, Christensen L, Hogdall C, Blaakaer J et al. Different risk factor profiles for mucinous and nonmucinous ovarian cancer: results from the Danish MALOVA study. Cancer Epidemiol Biomarkers Prev. 2007;16:1160-6.

Cite this article as: Priyadarshika M. A study of epidemiological and clinical profile of ovarian neoplasms at a tertiary care hospital. Int J Reprod Contracept Obstet Gynecol 2018;7:1953-7. 